\title{
EFFECT OF THE STRESS STATE TRIAXIALITY ON THE VALUE OF LIMIT STRAIN OF MICR0-VOID DEVELOPMENT IN S2355JR STEEL - NUMERICAL ANALYSIS
}

Abstract. This paper deals with the numerical analysis of plastic deformation and damage development in S235JR steel in complex stress states. The material Gurson Tvergaard Needleman (GTN) model was applied. The analysis was performed for notched bars subjected to tension. An attempt was made to investigate the effect of stress triaxiality on the value of critical strain of voids growth in the GTN model.

Keywords: ductile fracture, porous metal plasticity, GTN model, numerical analysis.

\section{Introduction}

Computing load carrying capacity of steel components of civil engineering structures at the design stage is a well-defined, relatively well-known process. It is far more difficult to make an analysis of existing structures operating under structural failure conditions (overload, damages to load bearing elements). In such a case, it is required to account for plastic reserve of the material load bearing and to apply the principles of fracture mechanics.

It is essential to employ a model of the material plastic flow. In the literature on the subject, one can find many solutions [1, 2], yet their practical applications, especially to complex stress states, could be sometimes restricted.

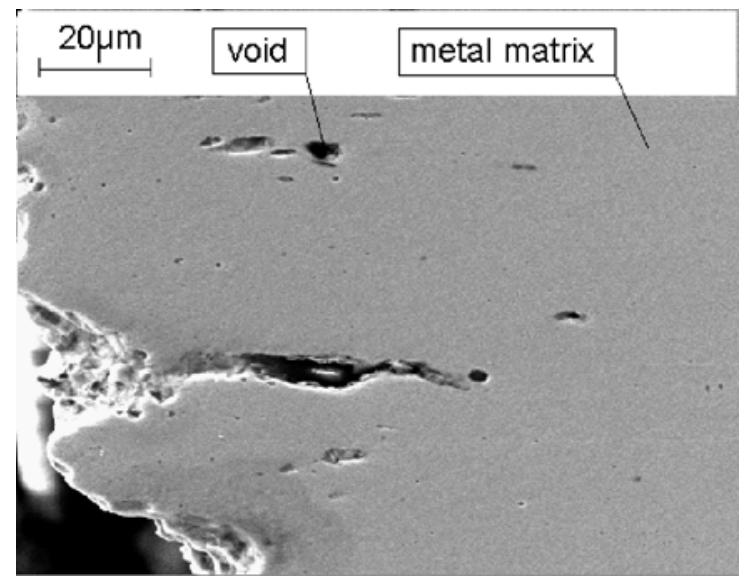

Fig. 1 Microstructure of investigated steel
Models of porous bodies offer a lot more possibilities [3, 4]. They describe fracture process by means of growth and coalescence of voids that are initiated on the boundary of the metallic matrix and the second phase particles (mainly sulphur and manganese compounds) - Fig. 1.

One of the solutions in the field is GTN model of the material. In order to obtain most reliable results, it is of key importance that the values of strains accompanying micro-void development are determined. According to many authors, the process of micro-void growth depends primarily on the degree of stress state triaxiality. That implies a similar pattern of changes will be demonstrated by strain values at the instant of rapid micro-void development and failure. The present paper aims at determining values of effective strains that accompany micro-void growth and the component failure as a function of a degree of stress state triaxiality.

\section{GTN model}

The description of the process of plastic fracture in metal alloys with technical applications is frequently presented using the model developed by Gurson [5], which was later modified by Tvergaard and Needelman. The model makes it possible to account both for the law of macroscopic plastic flow and the growth of micro-voids nucleating on inclusions and precipitations. The model application to the analysis of fracture process has been extensively investigated.

Void volume fraction is a basic parameter of the model. That is defined, in accordance with the formula below, as a ratio of a current micro-void volume to the sample volume:

\footnotetext{
* Wiktor Wcislik

Chair of Strength of Materials and Concrete Structures, Faculty of Civil and Environmental Engineering, Kielce University of Technology, Kielce, Poland, E-mail: wwcislik@tu.kielce.pl
} 


$$
f=\frac{V_{V}}{V}
$$

where: $V_{v}$ - current void volume fraction, $V$ - sample volume

Strains and stresses are determined at macroscopic level. Yield criterion is expressed as follows:

$$
\Phi=\frac{\sigma_{e q}^{2}}{\sigma_{M}^{2}}+2 q_{1} f \cosh \frac{3 q_{2} \sigma_{m}}{2 \sigma_{M}}-1-q_{3} f^{2}=0
$$

where: $\Phi$ - non-dilatational strain energy, $\sigma_{e q}$ - reduced stress in accordance with Huber Mises Hencky criterion, $\sigma_{M}$ - yield point, $\sigma_{m}$ - mean stresses (the arithmetic mean of major stresses), $q_{1}, q_{2}$, $q_{3}$ - Tvergaard coefficients, $f$ - current volume fraction of voids expressed by the following dependence:

$$
f= \begin{cases}f & \text { for } f \leq f_{c} \\ f_{c}+\frac{\overline{f_{F}}-f_{c}}{f_{F}-f_{c}}\left(f-f_{c}\right) & \text { for } f_{c}<f<f_{F} \\ \overline{f_{F}} & \text { for } f \geq f_{F}\end{cases}
$$

where: $f_{c}$ - critical void volume fraction corresponding to the lowered strength of the material, $f_{F}$ - void volume fraction corresponding to the loss of the material load-carrying capacity, $\overline{f_{F}}=\left[q_{1}+\left(q_{1}^{2}-\right.\right.$ $\left.\left.-q_{3}\right)^{0,5}\right] / q_{3}$

The process of void growth is closely related to the stress state, more precisely to the triaxiality degree defined as $\sigma_{m} / \sigma_{e q}$, where $\sigma_{m}$ - mean stress value, $\sigma_{e q}$ - equivalent tension, determined in accordance with the respective formulas:

$$
\begin{aligned}
& \sigma_{m}=\frac{\sigma_{11}+\sigma_{22}+\sigma_{33}}{3} \\
& \sigma_{e q}=\frac{1}{\sqrt{2}}\left[\left(\sigma_{1}-\sigma_{2}\right)^{2}+\left(\sigma_{2}-\sigma_{3}\right)^{2}+\left(\sigma_{3}-\sigma_{1}\right)^{2}\right]^{1 / 2}
\end{aligned}
$$

\section{Specimen types and investigation methodology}

In order to check how correct the computational results are and whether the GTN model parameters were selected properly, specimens with a ring notch underwent tension testing (Fig. 2a).
The specimens used in investigations were $12 \mathrm{~mm}$ in diameter, with the notch bottom radius $R=1,4$ and $10 \mathrm{~mm}$. Initial values of degree of stress state triaxiality in the axis of each specimen were equal to $1.943,1.026,0.670$, respectively.

Numerical simulation of the tension tests performed on components with a notch was conducted. Computations were carried with ABAQUS Version 6.7 software. Due to the transverse symmetry of the specimens used (where the notch bottom cross section surface was the symmetry surface) only one half of the specimen was modeled. The presence of the longitudinal axis of symmetry allowed for the use of axisymmetric model and simplifying the calculation. Basic mesh size was $1 \mathrm{~mm}$, but the mesh density around the notch was about three times higher. The model assumed blocked translation of the transverse symmetry surface. Loading was carried out at a controlled displacement of the end of the specimen. Standard axi-symmetrical CAX4R elements and the material GTN model were applied.

Computation results produced curves illustrating tension of components with a notch, graphs showing void volume fraction and values of strains accompanying the nucleation and rapid growth of micro-damages (in the specimen axis and on the notch surface). Notation convention for individual components of strains is presented in Fig. $2 b$ that shows coordinate systems for measurement in the specimen axis (on the left) and on the notch surface (right).

\section{Analysis of results}

The results of numerical computations for specimens with a notch are presented below. In all graphs, strain defined as the quotient of the specimen neck in the notch bottom by the initial diameter in this cross section, is an independent variable and a reference parameter.

The analysis of the tension curve for specimens with $1 \mathrm{~mm}$ notch (Fig. 3a) makes it possible to state that the stress maximum is reached when the strain $d / d_{0}$ (ratio of current diameter in the notch cross section to the initial diameter) equals 0.055 . Fig. $3 \mathrm{~b}$ shows that decreasing stress values are accompanied by a rapid increase in void volume fraction on the surface of the notch bottom, whereas the data in work [3] indicate void intensive development in the specimen axis. Rapid void growth was observed for the strain of 0.037 . The rate of micro-damage development is relatively constant until the strain reaches approx. 0.19 , after which the speed

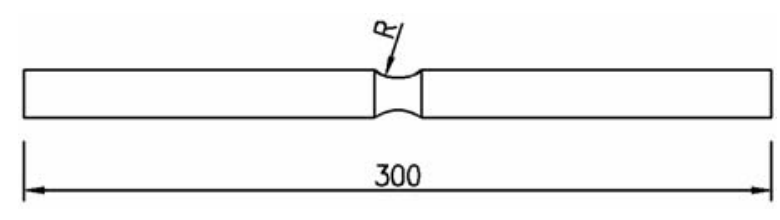

a)
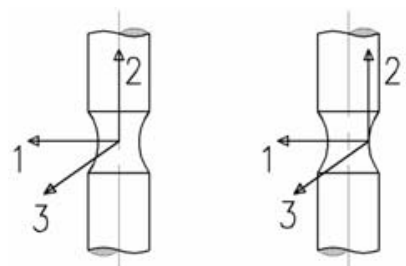

b)

Fig. 2 Specimens used in investigations (a) and notation convention for individual components of strains (b) 


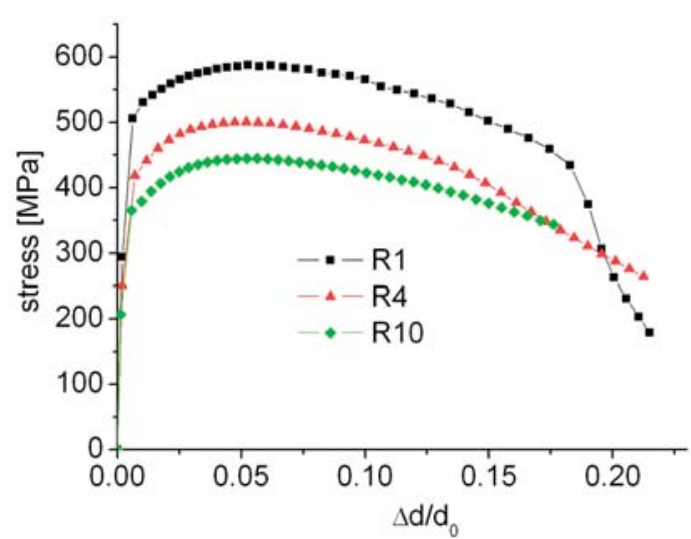

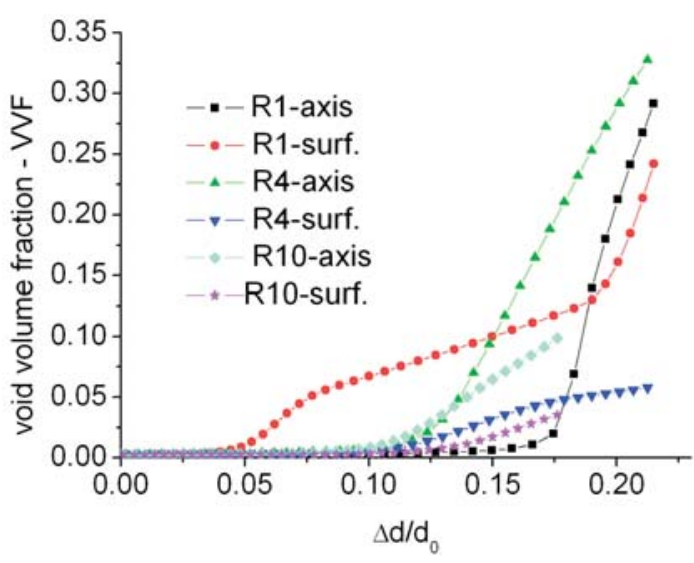

b)

Fig. 3 Numerically determined tension curves (a) and void volume fraction in the axis and on the notch surface of specimens (b)

of the process increases rapidly again. At the instant of failure, the void volume fraction in the cross section amounted to $30 \%$, which shows good congruence with the data in [3].

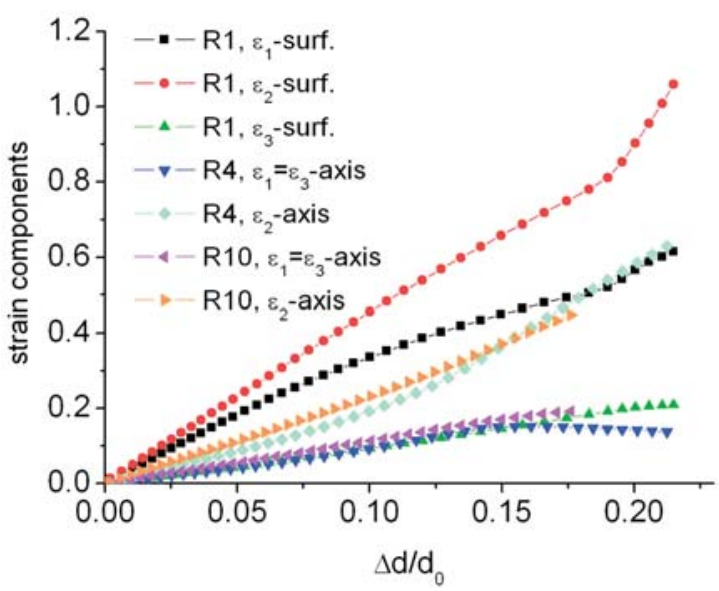

Fig. 4 Strain components in the areas of the highest void growth intensity

Fig. 4 shows a change in strain component values computed for the point of the highest intensity of micro-void development at the strain initial stage. At the point corresponding to a rapid increment in void fraction $\left(d / d_{0}=0.037\right)$, values of components $\varepsilon_{1}, \varepsilon_{2}$, $\varepsilon_{3}$ amounted to $0.13,0.17$ and 0.033 , respectively. The process of micro-void nucleation occurred for strains of $0.011,0.014$ and 0.0014 . The specimen failure took place for strain components that reached the values of $0.61,1.06$ and 0.21 . The value of the effective strain $\varepsilon_{e f}=\left(\varepsilon_{12}+\varepsilon_{22}+\varepsilon_{32}\right)^{0.5}$ that accompanied void development amounted to $\varepsilon_{\text {efdev }}=0.217$, whereas the effective strain at the instant of failure $\varepsilon_{\text {effail }}$ was 1.241 .

Micro-damage development in specimens with the notch bottom radius $4 \mathrm{~mm}$ demonstrates a slightly different character. The maximum in the stress graph is reached for the strain of 0.052 (Fig. 3a). Sudden growth in micro-damage volume fraction occurs a little later, after $d / d_{0}$ has reached the value of 0.11 (Fig. 3b). In contrast to $R=1 \mathrm{~mm}$ specimens, a more intensive development of microdamage occurs in the specimen axis. At the instant of failure, the void volume fraction amounted to 0.33 in the specimen axis, and to 0.06 on the notch bottom surface. According to [3], the failure of a specimen of similar geometry $(R=3.5 \mathrm{~mm})$ occurred when the void volume fraction amounted to 0.26 , which shows a good congruence of the results obtained.

Fig. 4 presents changes in strain components in the specimen axis. In the case discussed, $\varepsilon_{1}$ and $\varepsilon_{3}$ are radial components, therefore the dependence $\varepsilon_{1}=\varepsilon_{3}$ holds (Fig. 2b). Strain components at void nucleation in the specimen axis amounted to $\varepsilon_{1}=\varepsilon_{3}=0.0005$ and $\varepsilon_{2}=0.003$. For the strain value $d / d_{0}=0.11$ (the start of the sudden micro-void development process), strain components at the point reached the values $\varepsilon_{1}=\varepsilon_{3}=0.11$, whereas $\varepsilon_{2}=0.22$ (the effective value $\varepsilon_{\text {efdev }}=0.269$ ). The specimen failed when $\varepsilon_{1}=\varepsilon_{3}=$ $=0.14$, and $\varepsilon_{2}=0.63$ (Eeffail of the value of 0.66 ).

By conducting comparative analysis of results obtained for specimens $R=4$ and $R=10 \mathrm{~mm}$, numerous analogies can be found. The strength of specimens with $10 \mathrm{~mm}$ notch was obtained for the strain of 0.052 (Fig. 3a). Similarly to the previous case, the sudden development of micro-voids occurred when the material strength was exceeded, at the strain of 0.08 (Fig. 3b). It should be noted that the intensity of micro-void growth was decidedly higher in the specimen axis. At the instant of failure, the void volume fraction at that point amounted to 0.1 .

The character of strain increment at the point (in the specimen axis) is similar to linear (Fig. 4). The dependence $\varepsilon_{1}=\varepsilon_{3}$ holds, like before. Strain components at void nucleation were $\varepsilon_{1}=$ $=\varepsilon_{3}=0.0008$ and $\varepsilon_{2}=0.003$, whereas at the onset of rapid microvoid growth, strain components were $\varepsilon_{1}=\varepsilon_{3}=0.09$ and $\varepsilon_{2}=0.19$. At the instant of the specimen failure, the following values were obtained: $\varepsilon_{1}=\varepsilon_{3}=0.19$ and $\varepsilon_{2}=0.45$. Values of effective strains thus amounted to $\varepsilon_{\text {efdev }}=0.229$ at the instant of micro-void rapid growth, and to $\varepsilon_{\text {effail }}=0.52$ at the instant of failure. 
On the basis of analysis of strain components at the points of fracture initiation, it should be stated that no matter what the case discussed was, the components on the loading direction $\left(\varepsilon_{2}\right)$ showed the highest values. Rapid development of micro-damage occurred at effective strain values ranging from 0.217 , for specimens with $1 \mathrm{~mm}$ notch, to 0.269 , for $4 \mathrm{~mm}$ notch. The values obtained are presented in Fig. 5, which shows the dependence of the effective strain at the instant of void development on the corresponding degree of stress state triaxiality (determined numerically). Each point in Fig. 5 represents one type of specimen tested (differing in notch radius) and corresponding stress state triaxiality at the moment of sudden void growth. According to Fig. 5, with an increase in triaxiality degree, the value of strain necessary to start a rapid microdamage development also grows. The difference in strain values between extreme points amounted to $24 \%$.

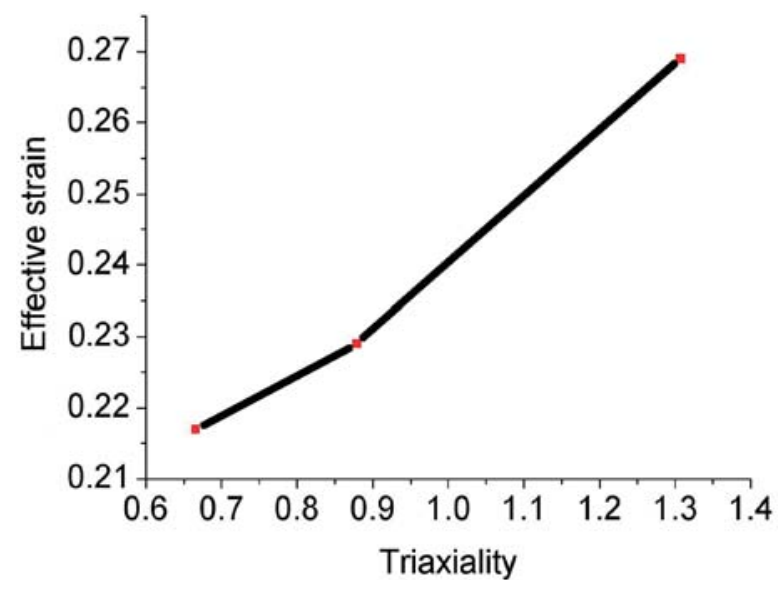

Fig. 5 Dependence of the strain accompanying rapid micro-damage development on the degree of stress triaxiality

The dependence that characterises strains accompanying specimen failure is of more complex nature. Then effective values ranged from 0.52 , for specimens with $R=10 \mathrm{~mm}$ notch, to 1.241 , for $1 \mathrm{~mm}$ notch. The character of changes in the effective strain is presented in Fig. 6. Each point in Fig. 6 represents one type of specimen tested (differing in notch radius) and corresponding stress state triaxiality at the moment of failure.

Within 0.7 - approx. 1.5 value range of the triaxiality degree, the dependence shows a degressive character. Yet, when the limit value of 1.5 is exceeded, the value of strains starts growing. For specimens under consideration, it was not possible to obtain triaxiality degrees higher than 1.678 , hence examining further the character of the curve could not be performed.

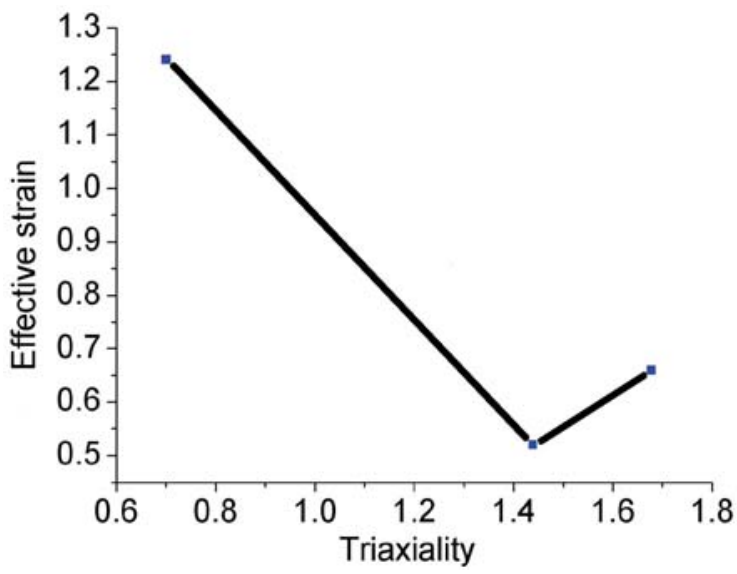

Fig. 6 Dependence of failure accompanying strain on the degree of stress triaxiality

It is supposed that strains of micro-void nucleation strongly depend on the material examined, primarily on the type of inclusions and precipitations. That provides an incentive to conduct numerical simulations at the microscopic level, and also to investigate other steel grades.

\section{Conclusion}

Numerical computation performed with GTN model made it possible to identify the areas of rapid micro-damage development, and hence the sites of initiation of ductile fracture. It was found out that for a sharp notch $(R=1 \mathrm{~mm})$, the failure process is initiated on the specimen surface. In specimens with relatively low degree of triaxiality $(R=4$ and $10 \mathrm{~mm}$ ), more pronounced microdamage development occurs in the component axis.

It was demonstrated that a decrease in the material strength is strongly related to the process of the material internal microdamage development. Void nucleation and growth in the specimen axis can be connected to an increase in the stress triaxiality degree. Such a relation was not found to exist for void development on the component surface.

\section{Acknowledgement:}

The publication is co-funded by the European Union from the European Social Fund, project: Teaching Potential Development Programme at the Kielce University of Technology: Education for Success. Human Capital Operational Programme, agreement No. UDA - POKL.04.01.01 - 00 - 175/08-00. 


\section{References}

[1] NEIMITZ, A.: Fracture Mechanics (in Polish). Wydawnictwo Naukowe PWN, Warsaw 1998.

[2] GOLASKI, L.: Elements of Experimental Fracture Mechanics (in Polish). Kielce University of Technology Publishing House, Kielce 1992.

[3] KOSSAKOWSKI, P., TRĄMPCZYNSKI, W.: S235JR Steel Failure Numerical Simulation Taking into Account the Effect of Microstructure Damage. Przeglad Mechaniczny, paper approved for publication.

[4] NOWAK, Z.: Identification Method in Mechanics of Ductile Materials with Damages (in Polish), Habilitation work, Inst. of Fundamental Technological Research, Polish Academy of Sciences (IPPT PAN), Warsaw 2006.

[5] GURSON, A. L. Continuum Theory of Ductile Rapture by Void Nucleation and Growth, Part I - Yield Criteria and Flow Rules for Porous Ductile Materials. J. of Eng. Materials and Technology, 1977, 99, pp. 2-15. 